${ }^{\circ}$ Entomologica Fennica. 22 October 2001

\title{
A new species of the genus Cryptoxilos Viereck (Hymenoptera: Braconidae: Euphorinae) from China
}

\author{
Xuexin Chen, Junhua He, Kees van Achterberg \& Yun Ma
}

Chen, X., He, J., van Achterberg, K. \& Ma, Y. 2001: A new species of the genus Cryptoxilos Viereck (Hymenoptera: Braconidae: Euphorinae) from China. — Entomol. Fennica 12: 108-111.

\begin{abstract}
A new species of the genus Cryptoxilos Viereck, 1911 is described from China. This is the first record of the genus from the East Palaearctic region. The new species is included in a key to the described species of the genus. The subgeneric name Cryptoxiloides Capek \& Capecki, 1979 is used to accommodate the Palaearctic species in the genus Cryptoxilos Viereck.

Xuexin Chen, Junhua He \& Yun Ma, Institute of Applied Entomology, Zhejiang University, Huajiachi Campus, Hangzhou, 310029, China; E-mail Xuexin Chen:xxchen@zju.edu.cn

Kees van Achterberg, Department of Entomology (Hymenoptera), National Museum of Natural History, P.O. Box 9517, 2300 R.A. Leiden, The Netherlands; E-mail: achterberg@naturalis.nnm.nl
\end{abstract}

Received 5 January 2001, accepted 11 February 2001

\section{Introduction}

Recently, a specimen belonging to the genus Cryptoxilos Viereck, 1911 (Hymenoptera: Braconidae: Euphorinae) was discovered by the first author among the unsorted part of the parasitic Hymenoptera collection at Zhejiang University, Hangzhou. This rare genus was not included in the revision of the Chinese Euphorinae (Chen \& van Achterberg 1997). The genus can be recognized by the aberrant venation (i.e. veins $\mathrm{m}$-cu and $2+3-\mathrm{CU} 1$ of forewing and vein cu-a of hindwing absent, vein 1-SC+R of hindwing unsclerotized, reduced, but vein $\mathrm{M}+\mathrm{CU} 1$ of forewing completely sclerotised (Fig. 1a)), the setose (and only in $q$ strongly converging) eyes, antenna with 12-14 segments, the labial palp with 2 segments, and the mesosoma with complete postpectal carina. Shaw $(1985,1997)$ includes the genus Cryptoxilos in the tribe Euphorini Foerster, 1862, but in this paper it is included in the tribe Cryptoxilonini Tobias, 1986. It has vein $\mathrm{M}+\mathrm{CU} 1$ of the forewing completely sclerotized, the labial palp with 2 segments, the mesosoma with a complete postpectal carina and the vein $1-\mathrm{SC}+\mathrm{R}$ of hindwing reduced.

Members of the genus are koinobiont endoparasitoids of adult Scolytidae (Coleoptera) (Shaw 1985, Shaw \& Huddleston 1991). The genus Cryptoxilos Viereck contains a few rarely collected species, with two species described from the Nearctic region, one from the Neotropical region and one from the Palaearctic region. In addition, some undescribed species are known from New Zealand and the Neotropical region. In this paper, a second Palaearctic species is reported from China, which is the first record of the genus for the East Palaearctic region (on the border of the Oriental region).

For the morphological terminology used in this paper, see van Achterberg (1993). 


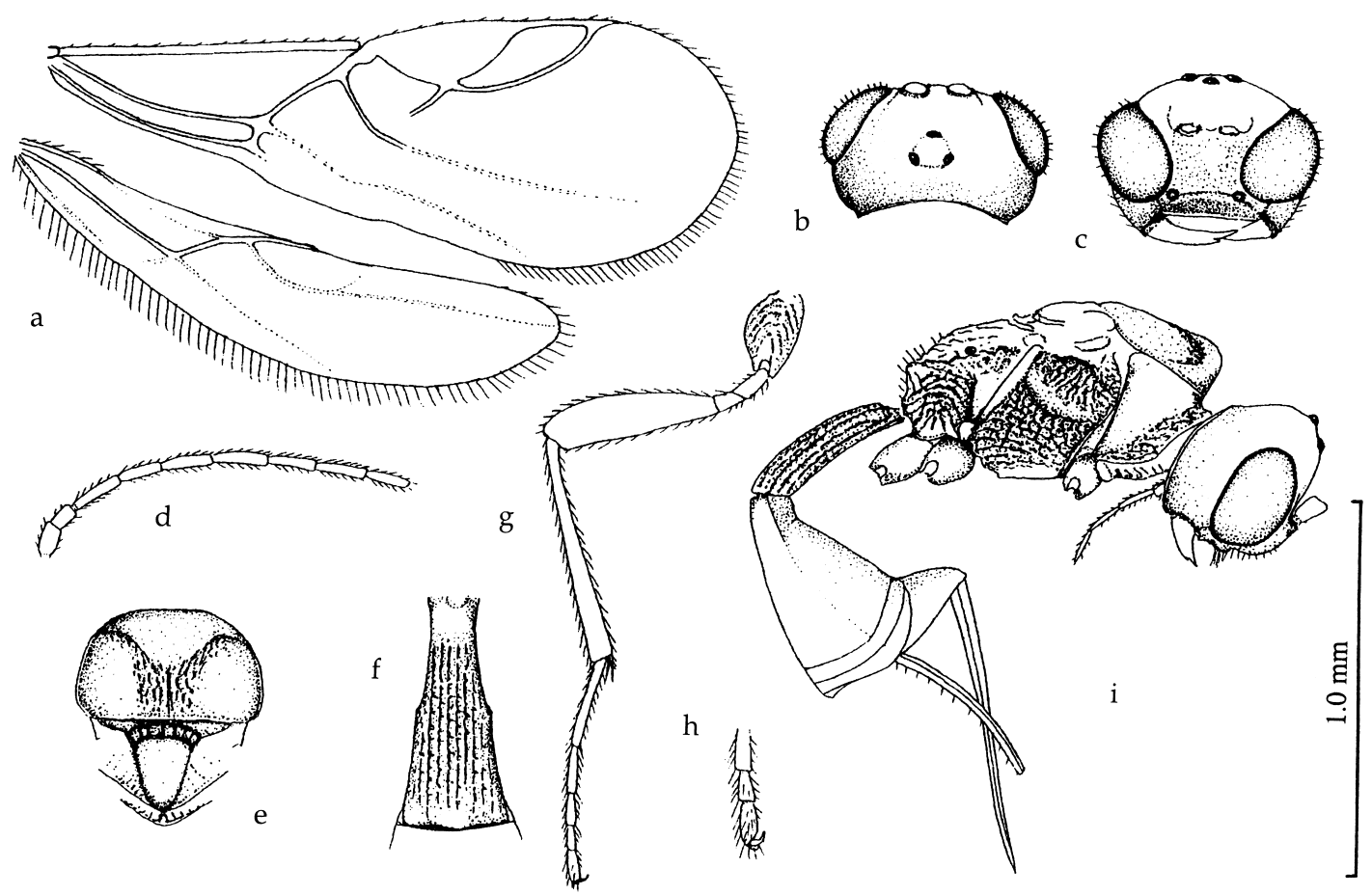

Fig. 1. Cryptoxilos pallipes sp. n., ᄋ, holotype. Wings (a); head, dorsal aspect (b); head, frontal aspect (c); antenna (lacking apical part) (d); mesothorax, dorsal aspect (e); first metasomal tergite, dorsal aspect (f); hind leg $(\mathrm{g})$; hind inner claw (h); habitus, lateral aspect (i). Scale lines: $1.0 \times(\mathrm{a}-\mathrm{e}, \mathrm{g}, \mathrm{i}), 1.25 \times(\mathrm{f})$ and $3.1 \times(\mathrm{h})$.

\section{Key to the species of the genus Cryptoxilos Viereck}

Note that the New World species have not been examined and are included on the basis of the limited information in their descriptions.

1. Vein 1-R1 of forewing about as long as length of pterostigma (Fig. 1B in Muesebeck 1936); face of $q$ strongly narrowed submedially, $\mathrm{X}$-shaped and minimum distance between eyes less than distance between outer margins of antennal sockets (Fig. 51 in Shaw 1997; but female of type species unknown); shape of vein SR1 of fore wing variable, often partly straight (Fig. 1 in Deyrup 1981); New World; (subgenus Cryptoxilos Viereck, 1911; type species: C. dichromorphus Viereck, 1911) ....

- Vein 1-R1 of forewing 0.3-0.5 times length of pterostigma (Figs. 1a, 2a); face of $\$$ moderately narrowed submedially, subrectangular and with the minimum distance between eyes about equal to distance between outer margins of antennal sockets (Figs 1c, 2h); vein SR1 of forewing evenly curved (Figs 1a, 2a); Old World; (subgenus Cryptoxiloides Čapek \& Čapecki, 1979; type species: C. cracoviensis (Čapek \& Čapecki, 1979))
2. Vein SR1 of forewing curved; third antennal segment hardly longer than fourth segment; vein 2-SR of forewing incomplete; antenna with 12 segments; Neotropical (Brazil) C. dichromorphus Viereck, 1911 Vein SR1 of forewing largely straight (Fig. 1B in Musesebeck 1936; Fig. 1 in Deyrup 1981); third antennal segment longer than fourth segment (Fig. 1 in Deyrup 1981); vein 2-SR of forewing variable; antenna with 13-14 segments; Nearctic (USA) .

3. Eyes of $O$ with fine short and sparse setae (in $0^{7}$ with only a few setae); face dark brown, contrasting with yellowish clypeus; antenna with 13 segments ............. C. lymantori Deyrup, 1981

- Eyes of both sexes conspicuously setose (Fig. 51 in Shaw 1997); face and clypeus brownish yellow, not contrasting; antenna with 14 segments

C. convergens Muesebeck, 1936

4. Notaulic area widely rugulose (Fig. 1e); malar suture present (Fig. 1c); anterior tentorial pits normal (Fig. 1c); mesopleuron largely sculptured (Fig. 1i); third antennal segment more slender, about 4 times as long as wide (Fig. 1d); vein SR of hindwing more curved basally (Fig. 1a); base of vein 2-SR of forewing situated close to base of vein SR1 (Fig. 1a); East Palaearctic (China) C. pallipes sp. $\mathrm{n}$.

- Notaulic area narrowly rugulose (Fig. 2e); malar suture 

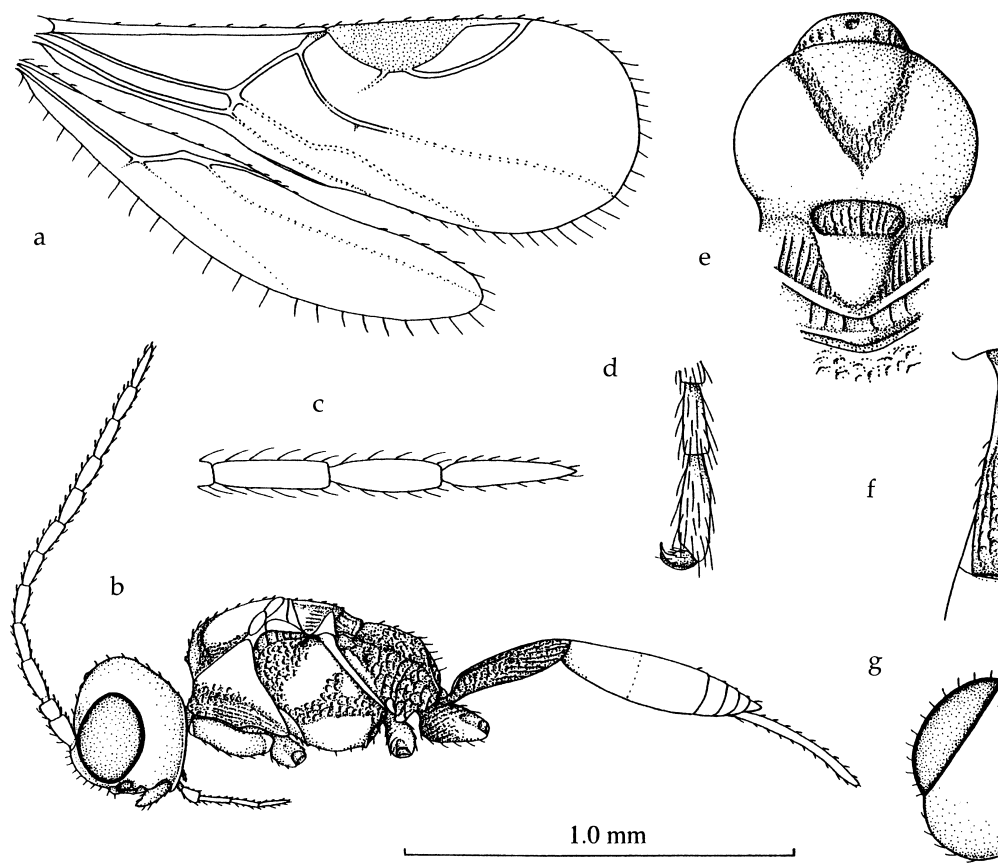

$\mathrm{h}$
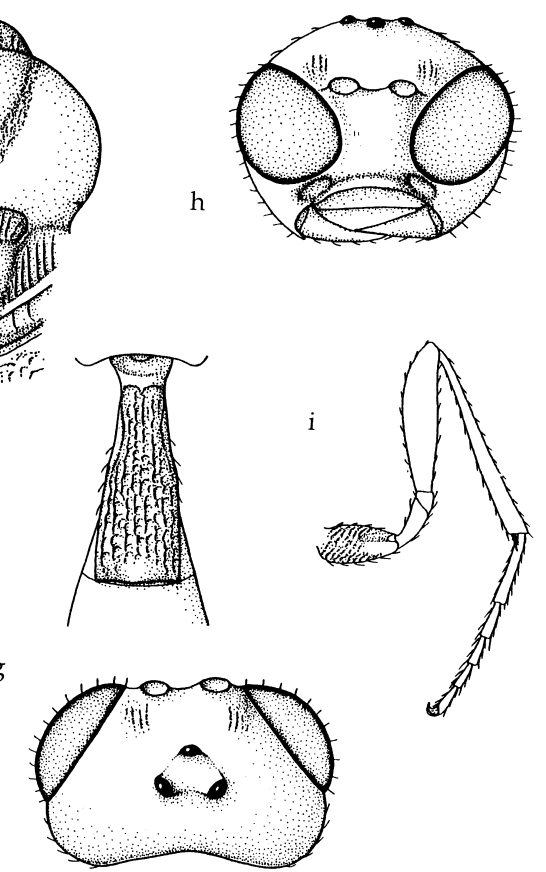

Fig. 2. Cryptoxilos cracoviensis (Čapek \& Čapecki), ᄋ, holotype. Wings (a); habitus, lateral aspect (b); apex of antenna (c); outer hind claw (d); thorax, dorsal aspect (e); first metasomal tergite, dorsal aspect (f); head, dorsal aspect (g); head, frontal aspect (h); hind leg (i). Scale lines: 1.0× (a, b, i), 2.8× (c, d) and 1.5× (e-h).

absent (Fig. 2h); anterior tentorial pits enlarged (Fig. 2h); mesopleuron largely smooth above and below precoxal sulcus (Fig. 2b); third antennal segment less slender, about 3 times as long as wide (Fig. 2b); vein SR of hind wing less curved basally (Fig. 2a); base of vein 2-SR of fore wing far separated from base of vein SR1 (Fig. 2a); West Palaearctic (Poland)

C. cracoviensis (Čapek \& Čapecki, 1979)

\section{Cryptoxilos pallipes sp. n. (Figs. 1a-i)}

Abbreviations used: ZAU = Zhejiang Agricultural University, Hangzhou; $\mathrm{OD}=$ diameter of posterior ocellus.

Material. Holotype, ( (ZAU), "[China], Zhejiang, Mt. Gutian, Kaihua, vii-viii.1990, Ma Yun, no. 905848”.

Holotype, , length of body $2.1 \mathrm{~mm}$, of forewing $1.8 \mathrm{~mm}$.

Head. Width of head in dorsal view 1.7 times its length; antenna broken, with 9 segments remaining, length of third segment 1.2 times fourth segment, length of third and fourth 4.0 and 3.3 times their width, respectively; length of maxillary palp 0.8 times height of head; maxillary palp with 5 segments, fourth segment about equal to fifth segment, third segment the longest; occipital carina complete and distinct, joining hypostomal carina ventrally; OOL:OD:POL $=7: 2: 2$; length of posterior side of stemmaticum as long as its lateral side; eye distinctly setose, length of eye in dorsal view 1.8 times temple; temple parallelsided behind eyes, posteriorly narrowed (Fig. 1b); temple, vertex and frons smooth; face narrow, nearly smooth, convex medially, its width as long as its height; intertentorial line 6.5 times tentorioocular line; clypeus narrow, its width 2.8 times its length, slanted ventrad, and ventral margin thin and straight; length of malar space 0.5 times basal width of mandible; mandible slender.

Mesosoma. Length of mesosoma 1.8 times its height; pronotal side ventrally largely smooth, remainder distinctly rugose; prosternum rugose; precoxal sulcus indistinct; mesopleuron largely distinctly rugose; metapleuron rugose; mesoscutum protruding anteriorly, middle and lateral lobes smooth; notauli distinct but shallow (Fig. 1e). Scutellar suture with six carinae; scutellum smooth and slightly convex; propodeum irregularly rugose, postero-medially concave, and latero- 
posteriorly distinctly protruding.

Wings. Forewing: length of vein 1-R1 0.6 times length of pterostigma; length of pterostigma 2.3 times its width; veins 2-SR and SR1 united basally and issuing from pterostigma and 2-SR incomplete (Fig. 1a); vein M+CU1 sclerotized; vein 1-SR+M present; veins m-cu, 1-CU1, 2-CU1, 3-CU1 and 21A absent; vein CU1a weak; basal and first discal cells densely setose. Hindwing: vein $1-\mathrm{SC}+\mathrm{R}$ absent, hind-margin with long setae.

Legs. Hind coxa distinctly rugose; length of hind femur, tibia and basitarsus 3.4, 8.0 and 8.4 times their width, respectively; length of outer and inner hind tibial spurs 0.2 and 0.3 times hind basitarsus, respectively.

Metasoma. First tergite longitudinally rugose dorsally, widened apically, ventrally open, its length 1.8 times its apical width, spiracles protruding and situated at middle, dorsope and laterope absent; following tergites smooth and glabrous; second metasomal suture absent; hypopygium medium-sized, glabrous; ovipositor sheath long, with sparse setae dorsally, its length 0.29 times forewing; ovipositor slender, straight, its length in exerted position 0.5 times forewing.

Colour. Reddish brown to dark brown, face, clypeus, palpi, ventral part of head, tegulae, legs, hypopygium and ovipositor yellow to brownish yellow; antenna brown, basal 4 segments paler than submedial segments; wing membrane hyaline with pale brown setae, pterostigma brown; veins brown to light brown.

Male. Unknown.

\author{
Biology and host. Unknown.
}

Acknowledgements. The authors wish to thank Dr. S. R. Shaw (Laramie, Wyoming) for sending photocopies, and Dr. M. R. Shaw (Edinburgh) for comments on the first draft of this paper. This project is supported by a grant (no. 39770112) of the China National Science Foundation.

\section{References}

Achterberg, C. van 1993: Illustrated key to the subfamilies of the Braconidae (Hymenoptera, Braconidae). - Zool. Verh. Leiden 283: 1-189.

Chen, X. \& Achterberg, C. van 1997: Revision of the subfamily Euphorinae (excluding the tribe Meteorini Cresson) (Hymenoptera: Braconidae) from China. Zool. Verh. Leiden 313: 1-217.

Deyrup, M. 1981: A new species of Cryptoxilos (Hymenoptera: Braconidae) attacking adult Lymantor decipens LeConte (Coleoptera: Scolytidae). — Ent. News 92: $177-180$.

Muesebeck, C. F. W. 1936: The genera of parasitic wasps of the braconid subfamily Euphorinae, with a review of the Nearctic species. - Misc. Publs. U. S. Dept. Agric. 241: 1-38.

Shaw, M. R. \& Huddleston, T. 1991: Classification and biology of braconid wasps (Hymenoptera: Braconidae). — Handbook Ident. Br. Ins. 7(11): 1-126.

Shaw, S. R. 1985: A phylogenetic study of the subfamilies Meteorinae and Euphorinae (Hymenoptera: Braconidae). — Entomography 3: 277-370.

Shaw, S. R. 1997: Subfamily Euphorinae. - In: Wharton, R.A., Marsh, P. M. \& Sharkey, M. J. (eds.), Manual of the New World genera of the family Braconidae (Hymenoptera). Special Publ. Int. Soc. Hym. 1, pp. 234-254. 